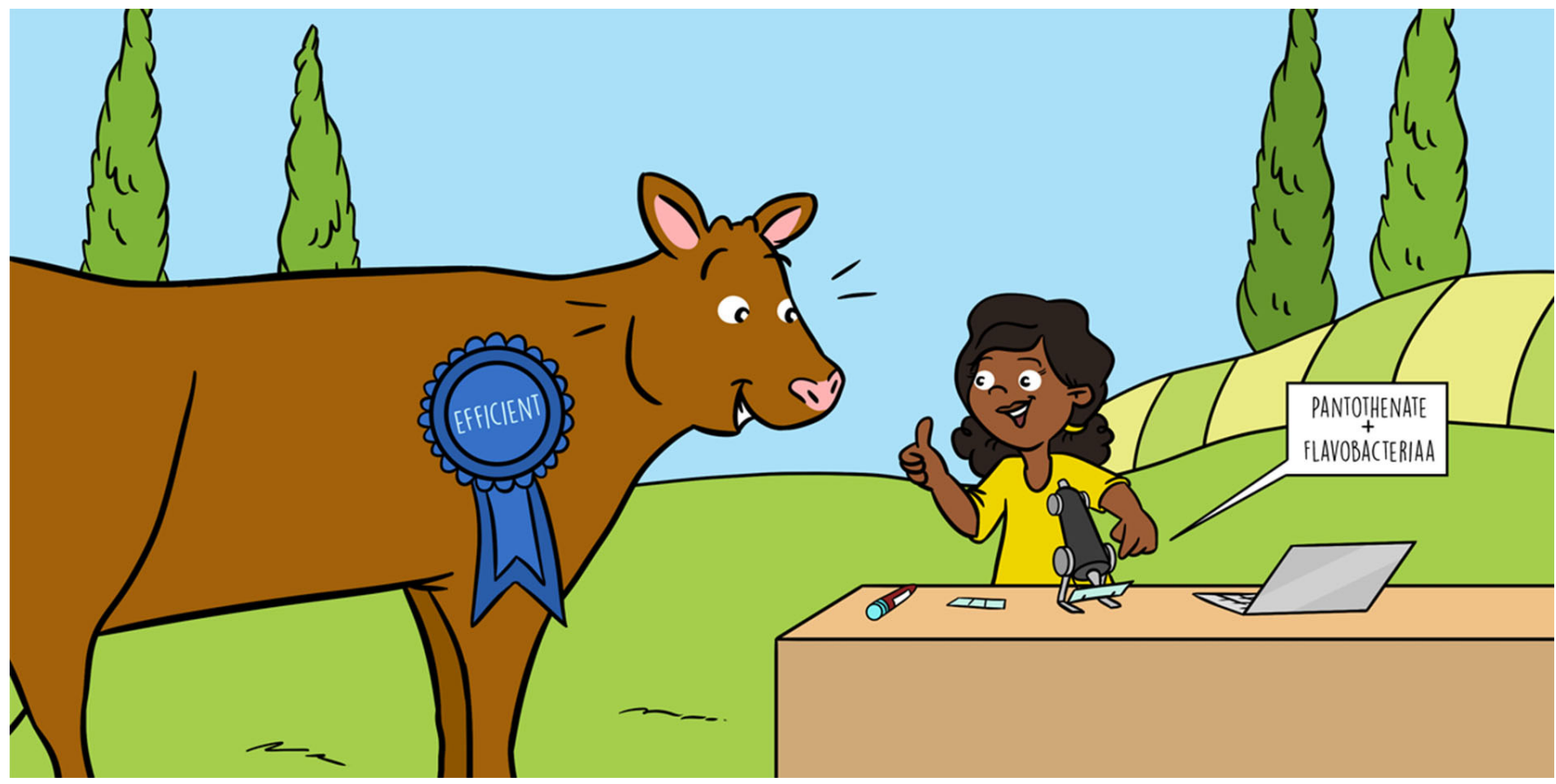

\title{
MICROBES HELP PREDICT MORE EFFICIENT CATTLE
}

\section{Brooke A. Clemmons and Phillip R. Myer*}

Department of Animal Science, University of Tennessee Institute of Agriculture, Knoxville, TN, United States

YOUNG REVIEWERS:

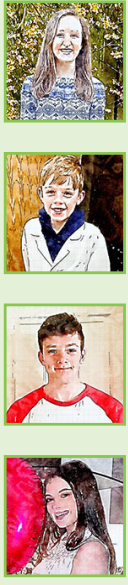

AGE: 15

HARRISON

AGE: 11

JOSHUA

AGE: 15

MEGAN

AGE: 15
CATHERINE

The number of people in the world is rapidly growing and with more people comes the need for more food. Luckily, cattle are a great resource to help provide more food! These animals can produce more protein than they consume, converting human-inedible grasses into high-quality protein for humans to eat. However, we can still improve this conversion of grasses to meat by making cattle more efficient at the process, otherwise known as making cattle more feed efficient. In this study, we identified stomach microbes and blood nutrients of feed-efficient cattle. Using computers, we were able to show that the nutrients in the blood could predict the microbes living in the stomachs of feed-efficient cattle. This work shows that microbes in the stomachs of cattle may help improve feed efficiency and can be used to predict which cattle are feed efficient.

\section{MAKING GRASS INTO MEAT}

Mammals that can get nutrients from plants by digesting them in a specialized stomach with the help of microbes.
Did you know that ruminants, like cattle, sheep, goats, and giraffes, have four-chambered stomachs that are specially made to help them digest plants? The first part of the four-chambered stomach is called 


\section{MICROBES}

Microscopic organisms that live all around us. Microbes include bacteria, fungi, and protozoa.

\section{DNA}

The material, present in nearly all living things, that is the carrier of genetic information a rumen, and this is where most of the plants that ruminants eat get broken down. The rumen of cattle can hold almost 50 gallons of food and water-that is a lot of food! The ruminants are able to break down plants that humans cannot eat because of the tiny microbes that live in the rumen. The microbes have special proteins, called enzymes, that can attack and digest the tough materials of the plant. Humans do not have the same enzymes that these microbes do, so ruminants can use plants and other foods that humans cannot use.

Since the microbes are the ones mostly breaking down the food that cows and other ruminants eat, they make a huge difference in how well the cows can use different kinds of feed to gain weight. Some cows and microbes are really good at breaking down the food and using the energy and other nutrients that come from it, and some are not so good at it. Cows that are good at breaking down food to get energy are called feed efficient. Feed-inefficient cows are not as good at extracting energy from food.

\section{COMPARING MICROBES AND NUTRIENTS IN DIFFERENT TYPES OF CATTLE}

Some of our recent research uses a combination of lab techniques and computer analyses to try to find a quick, easy, and cheap way of figuring out which cows are feed efficient, and how the rumen microbes may be helping them be better at using their food. First, we take blood samples from the cows. Then we collect the microbes in the rumen by placing a tube down the throat to the cow's stomach and pumping some of the stomach contents out. In the lab, we then break open the microbial cells to get the DNA from them, which allows us to identify which microbes are present. We also measure the amounts of different nutrients in the blood of cows that are able to gain more weight with less feed and those that do not gain as much weight with the same amount of food. After we find out which microbes are living in the gut of the cattle and the amounts of nutrients in the blood of the different animals, we analyze how these factors are different between feed-efficient cows and feed-inefficient cows. Finally, we use computers to calculate the relationships between the microbes and the nutrients, which allows us to see how the rumen microbes may be helping the cows be better at using the food we give them (Figure 1).

\section{WHAT DID WE FIND OUT?}

First, we looked at the microbes in feed-efficient and feed-inefficient cattle [1]. Since there are hundreds of different kinds of microbes that live in the rumen, we wanted to see if the feed-efficient and feed-inefficient cows had different kinds of microbes living in their rumen. We did not see any differences in the number of 
Figure 1

Finding ways to identify feed-efficient cattle through microbes. When cows eat grass, the grass feeds the microbes, which in turn feed the cow.

Researchers can examine the microbes in the rumen and the nutrients in the blood of cattle to see whether feed-efficient cattle have different microbes or nutrients than feed-inefficient cattle do.

\section{PANTOTHENATE}

Commonly known as Vitamin B5, and is important for the breakdown of the foods we eat into substances the body can use.

\section{COENZYME A (COA)}

An abundant and essential molecule that is involved in a lot of energy-related processes.

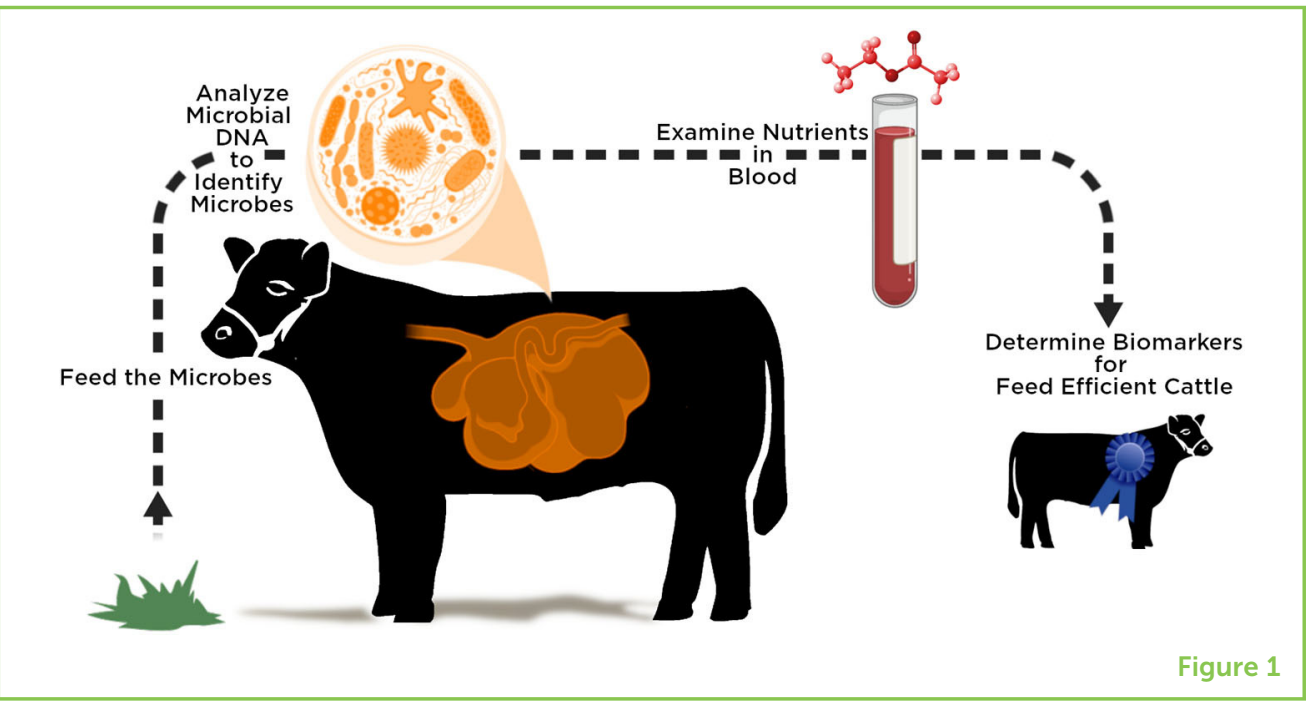

different kinds of microbes or any changes in how related the microbes were between the feed-efficient and the feed-inefficient cows. However, we did see differences in the numbers of specific microbes between the two groups of cattle. For example, the bacteria group of Flavobacteriia were greater in feed-efficient cows. We also observed that three different kinds of microbes seemed to be the ones responsible for causing the variation in the ability to use nutrients.

\section{MICROBES MAKE A DIFFERENCE!}

But even if there are different microbes, are they really making a difference in what nutrients the cows are getting? To answer this question, we looked at the nutrients found in the blood of the cows. First, we found that the feed-efficient and feed-inefficient cows had different amounts of certain nutrients [2]. One of those nutrients, called pantothenate, was greater in feed-efficient cows. Pantothenate is used to make a special molecule called coenzyme A (CoA). Coenzyme A is really important for many animals because it is involved in turning food into energy and in building muscle [3]. However, animals do not have the tools to turn pantothenate into CoA, but certain microbes do.

Knowing this, we wanted to see if there were any microbes from the rumen that could turn pantothenate into coenzyme A. We found that one group of bacteria, called Flavobacteriia, was greater in number in the rumen of feed-efficient cows. We then used computers that could perform very complex math to determine the relationship between the pantothenate and the Flavobacteriia. We found that the amount of pantothenate in the blood of cows could "predict" the amount of Flavobacteriia that was living in the rumen. So, the lower the amount of pantothenate in the blood, the lower the amount of Flavobacteriia living in the rumen of the cows. As the amount of pantothenate in 
the blood gets higher, the more Flavobacteriia are found living in the rumen.

This is really important for a couple of reasons. First, both pantothenate and Flavobacteriia are more abundant in feed-efficient cows. This might mean that both pantothenate and Flavobacteriia can be used by scientists and farmers to decide which cows are going to be better at using their food. Choosing and growing cows that are better at using their food means that the cows can grow faster and use less food, which is better for the environment [4]. Our findings also mean that the microbes in the rumen do change how the cows use the nutrients in food and the nutrients produced by microbes. Sometimes the small differences that scientists find between two groups of organisms do not actually affect the organisms. But our work provides more evidence that the differences in the rumen microbes can affect how the cows' bodies work to extract energy from food [5].

\section{HOW ARE WE GOING TO USE THIS INFORMATION IN THE FUTURE?}

We are hoping to be able to use this information in several ways. First, we hope to eventually develop a test that can use a little bit of blood to measure how efficient cows are at using the nutrients from their feed. Pantothenate may be one of those nutrients that can be used

\section{FEED EFFICIENCY}

A simple measure to determine the ability of cows to turn their feed into milk, milk components, or body weight. to measure feed efficiency, but we would also like to find others. We also hope to find more microbes that are changing or producing the nutrients that make ruminants better at using their food. If we know which microbes are making the nutrients that are helping the ruminants use their food efficiently, we may be able to feed more of those microbes to the ruminants to help them use their food even more efficiently. There is still a lot of work to do before we get to that point, but the work is very important because happy, healthy cows are better for people and better for the environment.

\section{ORIGINAL SOURCE ARTICLE}

Clemmons, B. A., Martino, C., Powers, J. B., Campagna, S. R., Voy, B. H., Donohoe, D. R., et al. 2019. Rumen bacteria and serum metabolites predictive of feed efficiency phenotypes in beef cattle. Sci. Rep. 9:19265. doi: 10.1038/s41598-019-55978-y

\section{REFERENCES}

1. Myer, P. R., Smith, T. P., Wells, J. E., Kuehn, L. A., and Freetly, H. C. 2015. Rumen microbiome from steers differing in feed efficiency. PLOS ONE 10:E0129174. doi: 10.1371/journal.pone.0129174 
2. Clemmons, B. A., Mihelic, R. I., Beckford, R. C., Powers, J. B., Melchior, E. A., McFarlane, Z. D., et al. 2017. Serum metabolites associated with feed efficiency in black angus steers. Metabolomics 13:147. doi: 10.1007/s11306-017-1282-z

3. Leonardi, R., Zhang, Y. M., Rock, C. O., and Jackowski, S. 2005. Coenzyme A: back in action. Prog. Lipid Res. 44:125-53. doi: 10.1016/j.plipres.2005.04.001

4. Myer, P., Clemmons, B., Schneider, L., and Ault, T. 2019. Microbiomes in ruminant protein production and food security. CAB Rev. 14:1-11. doi: 10.1079/PAVSNNR201914008

5. Clemmons, B. A., Powers, J. B., Campagna, S. R., Seay, T. B., Embree, M. M., and Myer, P. R. 2020. Rumen fluid metabolomics of beef steers differing in feed efficiency. Metabolomics 16:23. doi: 10.1007/s11306-020-1643-x

SUBMITTED: 04 March 2020; ACCEPTED: 13 August 2020;

PUBLISHED ONLINE: 25 September 2020.

EDITED BY: Johnathan J. Dalzell, Queen's University Belfast, United Kingdom

CITATION: Clemmons BA and Myer PR (2020) Microbes Help Predict More Efficient Cattle. Front. Young Minds 8:540393. doi: 10.3389/frym.2020.540393

CONFLICT OF INTEREST: The authors declare that the research was conducted in the absence of any commercial or financial relationships that could be construed as a potential conflict of interest.

COPYRIGHT @ 2020 Clemmons and Myer. This is an open-access article distributed under the terms of the Creative Commons Attribution License (CC BY). The use, distribution or reproduction in other forums is permitted, provided the original author(s) and the copyright owner(s) are credited and that the original publication in this journal is cited, in accordance with accepted academic practice. No use, distribution or reproduction is permitted which does not comply with these terms.

\section{YOUNG REVIEWERS}

\section{CATHERINE, AGE: 15}

I love music and singing, I play the violin and guitar, and I also enjoy writing! I am part of a highland dance troupe and volunteer with children at local kids clubs and guides. I enjoy attending youth events at my church and doing fitness. I hoped that by reviewing these articles I could learn about new and interesting stuff!
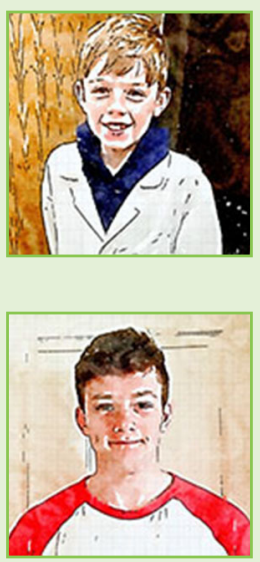

\section{HARRISON, AGE: 11}

I love playing sports, such as hockey and going running and chasing my dog! I also love discovering new things, but not new foods! Because I currently go to primary school I am excited to start my new secondary school and try lots of new subjects. My favorite subject at the minute is math.

\section{JOSHUA, AGE: 15}

I have been very interested in science from a young age and am fascinated by the wonders of the world. I like to know as much as I can about everything to be honest 

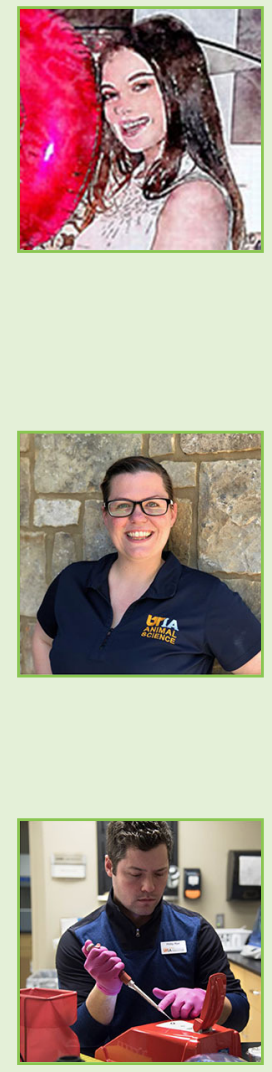

I am a bit of a nerd! I am interested in biology and chemistry and play rugby for my school.

\section{MEGAN, AGE: 15}

$\mathrm{Hi}$, I am Megan, my hobbies include musical theater, baking, and surfing (only during summer though!). I got involved with Frontiers for Young Minds as I really want to learn more about science and the world around me, I through reading these articles would be a good start!

\section{AUTHORS}

\section{BROOKE A. CLEMMONS}

Brooke A. Clemmons is a Ph.D. student in Animal Science in Knoxville, TN. She grew up in cities, but always loved farm animals. Brooke currently works with 132 cows to understand how different environmental things affect how cows use food. She specifically focuses on how different factors like pregnancy and genetics affect the microbes that live in the guts of cows, and how we can use those factors to make animals grow better and healthier.

\section{PHILLIP R. MYER}

Phillip R. Myer is an Assistant Professor at the University of Tennessee Department of Animal Science. He is interested in how microbes in beef cattle impact feed efficiency. Phillip is also interested in how beef cattle can interact with their microbes. His research group uses DNA technologies to help investigate these interactions. He hopes his research can help inform, improve, and be part of the solution to future global protein and food demand. *pmyer@utk.edu 